\title{
Evaluation Indexes of Degree of Closeness between Strategy and Project Portfolio Allocation
}

\author{
Libiao Bai, Sijun Bai \\ School of Management, Northwestern Polytechnical University, Xi'an, China \\ Email: hanshannuanyang@163.com, baisj@huading.net.cn
}

Received 19 November 2014; accepted 3 December 2014; published 13 January 2015

Copyright (C) 2015 by authors and Scientific Research Publishing Inc.

This work is licensed under the Creative Commons Attribution International License (CC BY). http://creativecommons.org/licenses/by/4.0/

c) (i) Open Access

\begin{abstract}
The main activities in project portfolio allocation management are selecting the right project components given a strategy. It is crucial to establish a scientific system of evaluation indexes to guarantee the closeness between strategy and project portfolio allocation optimally. With organizations growing in sizes, the functions and objectives of project components are becoming more and more different. It is necessary to set evaluation indexes of the degree of closeness from the perspectives of financial, market share, social effects, and so on according to the strategy-oriented process of project portfolio allocation. This paper proposes a project portfolio allocation process under strategic orientation and evaluation indexes of the degree of closeness between strategy and project portfolio allocation. This will help projects managers make portfolio allocation decisions.
\end{abstract}

\section{Keywords}

\section{Project Portfolio Allocation, Evaluation Indexes, Degree of Closeness, PPA Process}

\section{Introduction}

In the information era, with the growing competition in the market, project portfolio management (PPM) has become an effective means to enhance the competiveness of enterprises. In particular, project portfolio allocation (PPA) has been given more and more attention from industry experts and academic scholars because it can effectively help implement an organization's strategy.

PPA problems typically consist of resources allocation and schedule optimization. Many works emphasize the importance of resource allocation. The resources allocation problem is dynamic which should solve the large 
scale instances for a variety of resource allocation problems when we try to develop optimization models [1]. [2] considers the problem of multi-project resource allocation as a multi-channel queuing system and use language like GPSS to solve this problem. As same as the traditional projects, the resources allocation problem is also one of the most important problems in software project portfolios, and the systematic approach called the Best-Fitted Resource (BFR) methodology which considers complete skill sets of candidates can assign resources to tasks effectively [3]. In a multi-project matrix environment, the conflicts of resource allocation occur not only among different projects, but also among different activities even from the same project. A corporation will achieve higher organizational performance only if all of managers agree upon the resource allocation policy and try their best to implement it [4].

As one of the most important aspects of PPA problem, project scheduling for project portfolio management becomes more significant than ever before. Many scholars have thoroughly studied the project scheduling problem. Many of those models have been built to optimize this problem considering the scheduling process for a specific period only or at period one [5]-[7]. [8] addresses multi-project scheduling in a critical chain problem. In this paper, a multi-objective optimization model has been proposed and used to generate alternative schedules based on the importance of different projects and objectives [8]. Many other models are proposed to present the relationship between resources allocation and schedule optimization, which try to find the most optimal approach for solving the resource-constrained project scheduling problem [9]-[11]. The resource-constrained project scheduling problem (RCPSP) with a fixed date for every activity has the objective to complete the task in quality within the established deadline [12]. In the resource-constrained project scheduling problem, it is required to restart a fixed setup time while an activity is began, all of activities are interrelated by finish to start type precedence relations with the time lag of the minimum [13]. In order to effectively tackle the resourceconstrained project scheduling problem, two alternative approaches, FLP and PABC, have been proposed and applied into measure the relationship between resource and project scheduling, also the effectiveness of these approaches for RCPSP are showed by a series of computational experiments [14].

We can see the followings from the existing literature. The studies on the topics of PPA, including resources allocation, schedule optimization and RCPSP, have made great contributions to enhance organizational competitiveness, but they have rarely analyzed the evaluation indexes. As a result, the degree of closeness strategy and PPA cannot be scientifically measured. In this paper, we will propose a process model to analyze the relationship between strategy and PPA firstly. Then we will try to propose a system of evaluation indexes of the degree of closeness on the basis of the process model.

This paper is structured as follows. We propose a process model for PPA in Section 2. In Section 3 we will propose the system of evaluation indexes of the degree of closeness. The final section provides the conclusions.

\section{PPA Process Based on the Degree of Closeness to Strategy}

This section introduces the traditional PPA process firstly. In order to combine with organizational strategy, this section also puts forward a PPA process based on its degree of closeness to strategy.

\subsection{Traditional PPA Process}

The process of traditional PPA is divided into four stages: concept, feasibility study, selection and implementation [15], which is shown in Figure 1:

1) Concept stage of PPA

In this stage, the main work is to prepare project proposals, which will analyze the necessity of the project to be implemented. In order to prepare project proposals, the market analysts, technicians and manager should analyze the impact of the project being implemented on other ongoing projects.

2) Feasibility study stage of PPA

Organization's situation and strategic objectives, analysis the superiority of the proposed projects in the first stage from the aspects of risk/benefit, the project capacity (e.g., implementation capacity, financial capacity, technical capacity, management capacity), and technical superiority and competitive barriers will provide a reference to select the components of PPA.

3) Component selection stage of PPA

Based on the result of feasibility study in the second stage, all project components and configured tentatively. Previous project experience describing the degree of closeness between project components and organization's 


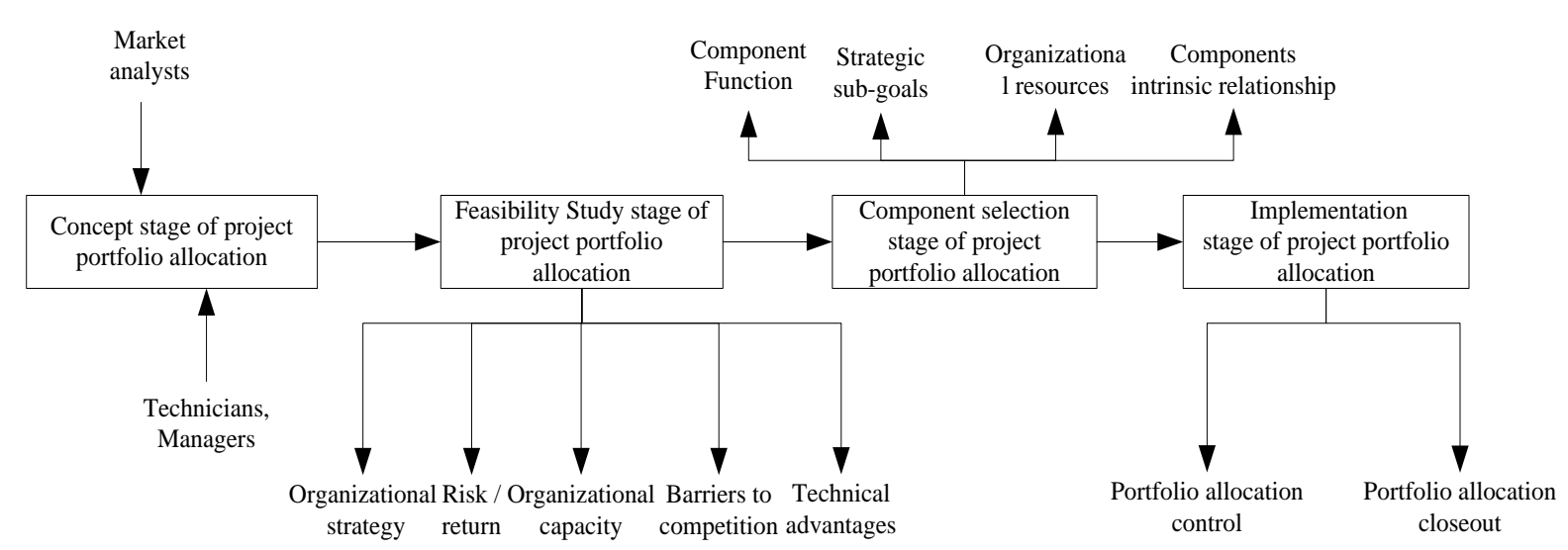

Figure 1. Four stages of traditional PPA.

strategic objectives are utilized. The best project components are selected and a trial allocation is formed. The most important work in this stage is to make sure the trial allocation meets organizational resource constraints and internal relationships among components.

4) Implementation stage of PPA

Implementation stage is the main part of PPA, including portfolio allocation implementation, allocation adjustment and optimization. How to allocate the components? How to implement the priority components and how to implement the component issues? These are the key issues in this stage. With these issues, organizers analyze variations and the reasons for them in the process of implementation, develop and implement appropriate corrective measures to optimize the allocation of portfolio solutions to ensure the PPA is aligned with the organization's strategy during the process of project portfolio implementation.

\subsection{PPA Process Based on the Degree of Closeness to Strategy}

The biggest difference between the PPA process based on the degree of closeness to strategy and traditional PPA process is the former takes into account the organization's strategic influence on portfolio, which subdivides organization strategy in details and makes it loaded with each project to be implemented. Therefore, a reasonable PPA process would become the primary guarantee that the organization's strategic objectives are to be achieved.

In this section, organization strategy will be decomposed to optimize traditional project portfolio process. On this basis, the process of PPA for the degree of closeness to strategy has been proposed, which is shown in Figure 2.

In Figure 2, the strategic target has been divided into two major parts: the financial and the non-financial strategic targets. The PPA process based on the degree of closeness to strategy is as below.

1) Build the collection of alternative projects

The collection of alternative projects is based on the need of the development of enterprises. Managers collect, collate, analyze and improve the information on the projects which will likely bring new opportunities for organizational development, generate synergies among projects in terms of costs, expected returns, client satisfaction, risk, organizational conditions, internal human resources, hardware and software. Managers also analyze the state of the implemented project components, put the projects which meet the organization's strategic objectives and development needs into a same collection, and build a "project pool" under the guidance of the strategy.

2) Alternative project evaluation

The steps for detailed implementation in this stage are as follows.

a) Collect the information on the projects to be implemented: analyze the possibility of projects by collecting and organizing the information and data.

b) Evaluate the projects to be implemented: evaluate the projects from the aspects of financial, non-financial and the degree of closeness to strategy, group the projects which meet financial and non-financial constraints into a "project pool". For those projects which cannot meet financial and non-financial constraints but meet the strategic needs, they can also be grouped into the "project pool" to ensure the PPA is close to strategy. All other remaining projects are then removed. 


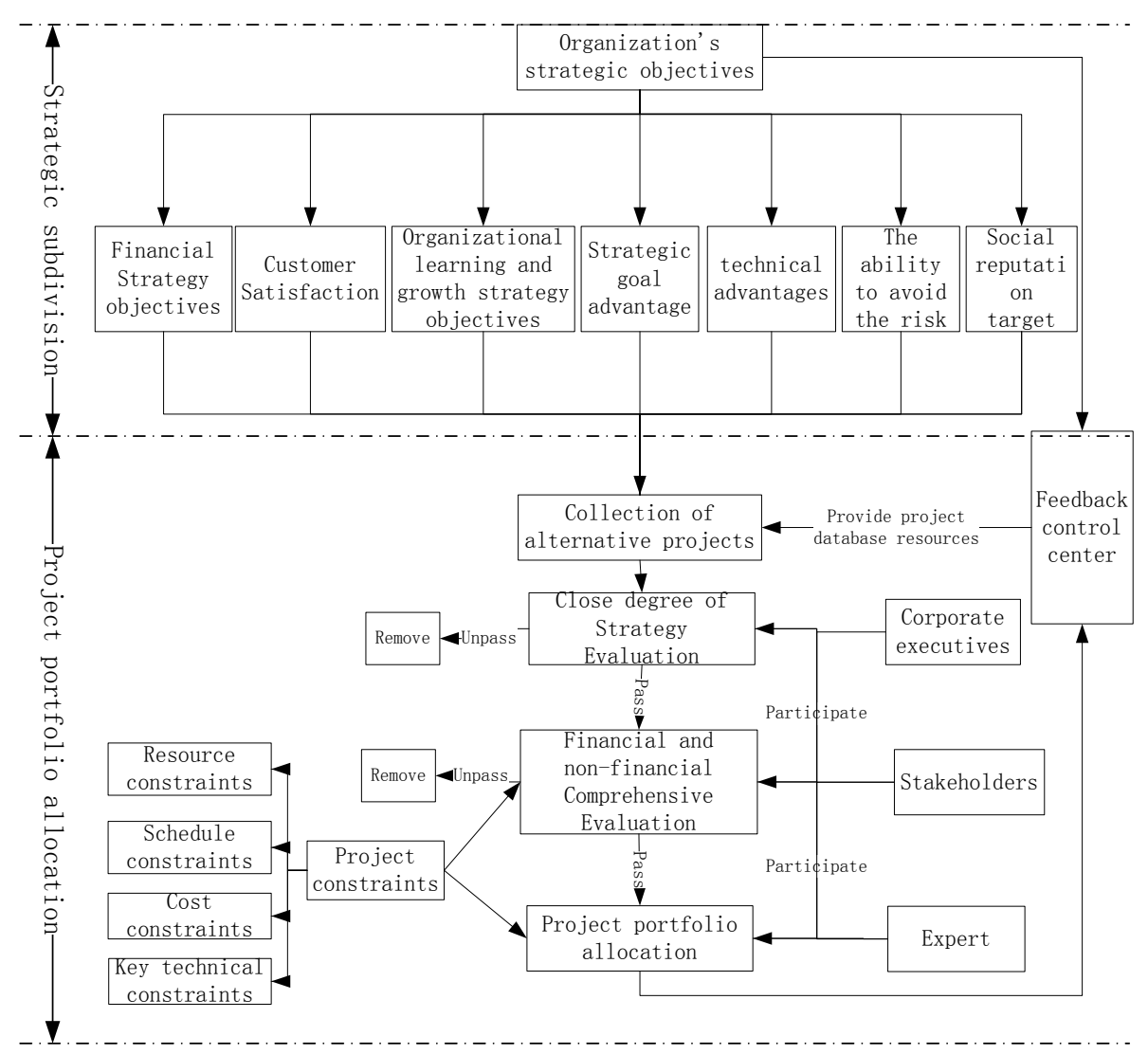

Figure 2. PPA process based on the degree of closeness to strategy.

3) Project portfolio allocation

The ultimate goal of PPA models is to ensure all the project components to be implemented can achieve the best selection and the optimal allocation in the organization. Senior management, experts and stakeholders participate in project evaluation and feasibility studies at this stage of PPA selection to make sure the components bearing the organization's strategy effectively. At the same time, meta-analysis and feedback of the portfolio allocation process are used to enrich and complement the content of project information database, which will support the next stage of PPA.

\subsection{The Advantages of the PPA Process Based on the Degree of Closeness to Strategy}

Traditional division of portfolio allocation process is based on the PPA's implementation phase, which overemphasizes the evaluation of project portfolio components. However, it does not take strategy into account causing the process to deviate from the strategy. Due to the lack of scientific management allocation tools and process implementation guidance, most organizations still use the single project management approach to managing the portfolio allocation. It will bring a strong randomness in the process of project portfolio selection and portfolio allocation in this kind of management pattern. This is a very important flaw. Consequently, the managers cannot allocate the resources at the level of organization's strategic objectives. The PPA process based on the degree of closeness is designed to solve this problem. This process is based on the decomposition of the strategic objectives effectively which means each allocation component is able to undertake a sub-strategic objective and realize the organization strategy effectively. Meanwhile, this process can combine with organizational changes and the competition of market environment and dynamically adjust the allocation component so that it can keep a high degree of closeness to strategy.

Compared with traditional allocation process, the advantage of PPA process based on the degree of closeness is that it has created a virtuous cycle between strategy and project portfolio management, which help achieve the organization strategy by project management. Through the layers of tissue segmentation strategy, building stra- 
tegic objectives at different levels (enterprise level, portfolio level, functional level) to achieve a level of commitment to the strategic objectives division project components; at the same time, in the implementation of the project portfolio allocation process, strategic organizational layers of sub-goals for project implementation can be achieved in accordance with the organization during the project portfolio allocation strategies for the implementation of the management objective dynamic control, ensuring strategic goal of optimization. Therefore, based on the portfolio strategy nearness of the configuration process presented in this chapter with respect to the traditional configuration process, the organization in achieving strategic objectives, to ensure that organizations achieve upgrade cycle has a huge advantage and reasonable. Therefore, the process of PPA built in this section has enormous advantages in achieving the sustainable development of organization.

\section{Evaluation Indexes System for the Degree of Closeness between Strategy and PPA}

\subsection{Principles of Building the System of Evaluation Indexes of the Degree of Closeness}

In order to ensure the validity of the index system, we should follow the following principles.

1) Dynamic

This index system should be able to dynamically adjust with the organization strategy adjustment. The weight of each index should follow strategic changes, so that it can dynamically and scientifically reflect the relationship between portfolio allocation component and strategy.

2) Systematic

In order to ensure the index system is scientific and systematic, we should make a comprehensive analysis of the internal relations among various factors during the process of building the index system. This means the index system should try to achieve the system-wide optimization.

3) Comparability

This evaluation index system is for all organizations and all project components. Therefore, it must be across various types of enterprises to achieve the quantitative comparison.

4) Relative independence

This principle means each index in this system should keep independent to prevent redundancy.

\subsection{Construction of the System of Evaluation Index for the Degree of Closeness}

As Figure 2 shows, the strategic target has been divided into financial and non-financial strategic targets. Financial objectives are mainly used to measure the progress of achieving strategic objectives and are familiar to managers. However, using the financial indexes only is insufficient. It is necessary to use non-financial indexes for auxiliary measurement and calculation. There are lots of non-financial indexes used to measure the degree organization's strategic objectives achieved. We can group the non-financial indexes into six categories [16]: customer satisfaction, strategic goals advantage, organizational growth, technical superiority target formation, risk avoidance capability and social reputation. On the basis of these categories, this paper incorporates strategy into the area of evaluation indexes. Subdividing the non-financial indexes into this sub-index according to the management indexes by Standardization Project Management Institute [17], we obtain the system of evaluation indexes of the degree of closeness between strategy and PPA, as shown in Table 1.

\subsection{Optimization of Evaluation Indexes of the Degree of Closeness between Strategy and PPA}

In the Section 3.2, this paper has initially constructed evaluation indexes system for the degree of closeness between strategy and PPA from the aspects of financial index, customer satisfaction, strategic objectives, organization growth, the advantage of technical advantages, the ability to avoid the risk and social reputation. However, this index system is based on the improvement of the existing literature and its scientific validity cannot be guaranteed. To solve this problem, it is necessary to optimize the index system. In this paper we invited 10 experts in the area of project management form the PMRC (Project Management Research Committee). We use the expert assessment method to achieve optimal allocation index system of strategy upgrade. The process of this optimization is shown as below.

1) Sort out the evaluation indexes of the degree of closeness which need to be studied, then distribute the 


\begin{tabular}{|c|c|c|}
\hline \multirow{7}{*}{$\begin{array}{c}\text { Financial } \\
\text { Indexes }\end{array}$} & \multicolumn{2}{|c|}{ NPV } \\
\hline & \multicolumn{2}{|c|}{ Return on investment } \\
\hline & \multicolumn{2}{|c|}{ Payback period } \\
\hline & \multicolumn{2}{|c|}{ Capital turnover } \\
\hline & \multicolumn{2}{|c|}{ Financing methods } \\
\hline & \multicolumn{2}{|c|}{ Inventory turnover } \\
\hline & \multicolumn{2}{|c|}{ Profit rate } \\
\hline \multirow{6}{*}{$\begin{array}{c}\text { n-financial } \\
\text { indexes }\end{array}$} & Customer satisfaction & Technical superiority target formation \\
\hline & $\begin{array}{l}\text { 1) Customer relationship evaluation value for strategic results; } \\
\text { 2) The strategic results to customers effects; } \\
\text { 3) The degree of satisfaction of customer expectations; } \\
\text { 4) Customer loyalty; } \\
\text { 5) Lost customer return rate. }\end{array}$ & $\begin{array}{l}\text { 1) Technology leadership degree; } \\
\text { 2) Architecture consistency; } \\
\text { 3) The adoption of new technology achievements; } \\
\text { 4) The technology can be solid; } \\
\text { 5) The technical maturity and reliability; } \\
\text { 6) A number of patents and property rights. }\end{array}$ \\
\hline & Strategic goals advantage & Risk avoidance capability \\
\hline & $\begin{array}{l}\text { 1) Fitness of strategic objectives and business development; } \\
\text { 2) The degree of strategic objectives can be broken down; } \\
\text { 3) The image of the product enhanced; } \\
\text { 4) The degree of corporate reputation enhanced; } \\
\text { 5) The competitiveness of the enterprise market enhanced. }\end{array}$ & $\begin{array}{l}\text { 1) Identification of risk factors complete degree; } \\
\text { 2) A reasonable degree of risk to the organization; } \\
\text { 3) Timeliness and effectiveness of risk measures; } \\
\text { 4) The risk of handling scientific; } \\
\text { 5) The accuracy of risk prediction. }\end{array}$ \\
\hline & Organizational growth & Social reputation \\
\hline & $\begin{array}{l}\text { 1) Professional training capability; } \\
\text { 2) Employee satisfaction; } \\
\text { 3) Enhance organizational project management maturity; } \\
\text { 4) The members of the organization to enhance collaboration } \\
\text { capabilities earnings; } \\
\text { 5) Integration and sharing of resources to bring; } \\
\text { 6) The optimization of the management process. }\end{array}$ & $\begin{array}{l}\text { 1) The degree of organization of social responsibility; } \\
\text { 2) The organization of social appeal; } \\
\text { 3) Good public relations degree; } \\
\text { 4) QOS reputation; } \\
\text { 5) The social image recognition; } \\
\text { 6) The preference of product for the customer. }\end{array}$ \\
\hline
\end{tabular}

evaluation forms to invited experts, ask them to sort all indexes in this system according to the importance, ranging from 1 to 10 . If the experts believe that there is a need to add or delete an indicator, they can also state that. The basic format of the table is shown in Table 2:

2) Recycle and sort out the experts' advice, set the weight of experts' advice according to the reputation of the experts in the area of this research, management experience and their published literature. This paper only takes the financial indexes as an example to analyze the experts' advice due to page limit. The summarization of expert's opinions on financial evaluation indexes of the degree of closeness between strategy and project portfolio allocation is shown in Table 3:

3) Comprehensive value of evaluation indexes of the degree of closeness between strategy and PPA

According to Table 3, we can calculate the comprehensive evaluation value of each sub-index by using the weight sum method. If the comprehensive evaluation value $V_{I_{n}}<5$, which means the index $I_{n}$ has little effect on the strategic and portfolio allocation, then $I_{n}$ will be deleted from the system of evaluation indexes. Take the NPV as a case, it is easy to calculate the comprehensive value $V_{I_{1}}$ :

$$
\begin{aligned}
V_{I_{1}} & =0.08 \times 9+0.12 \times 7+0.15 \times 5+0.05 \times 3+0.09 \times 8+0.13 \times 7+0.08 \times 6+0.15 \times 9+0.09 \times 8+0.06 \times 4 \\
& =6.27
\end{aligned}
$$

Similarly, we can get the comprehensive evaluation value of other indexes. The results are shown in Table 3 . 4) Index optimization 
Table 2. Table of consultation for evaluation indexes.

\begin{tabular}{cccccc}
\hline Indexes & $I_{1}$ & $I_{2}$ & $I_{3}$ & $\cdots \cdots$ & $I_{n}$ \\
\hline Evaluation value & & & \\
Other comments & & & \\
\hline
\end{tabular}

Note: $I_{n}$ represents the $n$th index to be optimized in the evaluation indexes system.

Table 3. Summarization of expert's opinions on financial evaluation indexes of the degree of closeness between strategy and PPA.

\begin{tabular}{|c|c|c|c|c|c|c|c|}
\hline Expert weight $\quad$ Index & NPV $\quad I_{1}$ & $\begin{array}{c}\text { return on } \\
\text { investment } I_{2}\end{array}$ & $\begin{array}{c}\text { payback } \\
\text { period } I_{3}\end{array}$ & $\begin{array}{c}\text { capital } \\
\text { turnover } I_{4}\end{array}$ & $\begin{array}{l}\text { Financing } \\
\text { methods } I_{5}\end{array}$ & $\begin{array}{l}\text { Inventory } \\
\text { turnover } I_{6}\end{array}$ & $\begin{array}{ll}\text { Profitrate } I_{7}\end{array}$ \\
\hline 0.08 & 9 & 6 & 5 & 4 & 6 & 5 & 8 \\
\hline 0.12 & 7 & 6 & 9 & 7 & 8 & 6 & 7 \\
\hline 0.15 & 5 & 5 & 7 & 6 & 6 & 7 & 8 \\
\hline 0.05 & 3 & 4 & 7 & 2 & 8 & 5 & 6 \\
\hline 0.09 & 8 & 6 & 3 & 5 & 5 & 4 & 5 \\
\hline 0.13 & 7 & 5 & 8 & 4 & 8 & 3 & 6 \\
\hline 0.08 & 6 & 6 & 9 & 8 & 8 & 7 & 8 \\
\hline 0.15 & 9 & 5 & 7 & 9 & 9 & 6 & 7 \\
\hline 0.09 & 8 & 4 & 3 & 5 & 8 & 5 & 6 \\
\hline 0.06 & 4 & 5 & 9 & 6 & 6 & 3 & 5 \\
\hline $\begin{array}{l}\text { Comprehensive } \\
\text { value } V_{I_{n}}\end{array}$ & 6.27 & 4.9 & 6.22 & 4.82 & 6.82 & 4.72 & 6.33 \\
\hline
\end{tabular}

As shown in Table 3, the comprehensive evaluation values of other indexes are 6.27, 4.9, 6.22, 4.82, 6.82, 472, 6.33. We delete the indexes with the comprehensive value less than 5 . We then can obtain the new financial evaluation indexes of the degree of closeness between strategy and PPA: financing methods, payback period, return on investment, profit rate. Using the same approach, we can obtain results of evaluation indexes of the degree of closeness between strategy and PPA after optimization. This is shown in Figure 3.

\section{Conclusion}

According to the project portfolio allocation process under strategic orientation, this paper proposes a PPA process for the degree of closeness based on the introduction of traditional PPA process. In order to ensure the scientific validity of the index system, we introduce the principles for building the system of evaluation indexes, then tentatively construct the system of evaluation indexes of the degree of closeness between strategy and PPA from the aspects of financial index, customer satisfaction, strategic objectives, organization growth, the advantage of technical advantages, the ability to avoid the risk and social reputation. However, this index system is based on the improvement of the existing literature, so its scientific validity cannot be guaranteed. In order to solve this problem, this paper employs optimization. Finally, this paper proposes a new system of evaluation indexes of the degree of closeness between strategy and PPA. This new system has enormous advantages in achieving the sustainable development of organizations. In short, the system of evaluation indexes proposed in this paper not only rectifies the weaknesses and deficiencies in previous studies of PPA, but also makes a great contribution to helping the manager find the best project portfolio allocation from the set of projects to be implemented. 


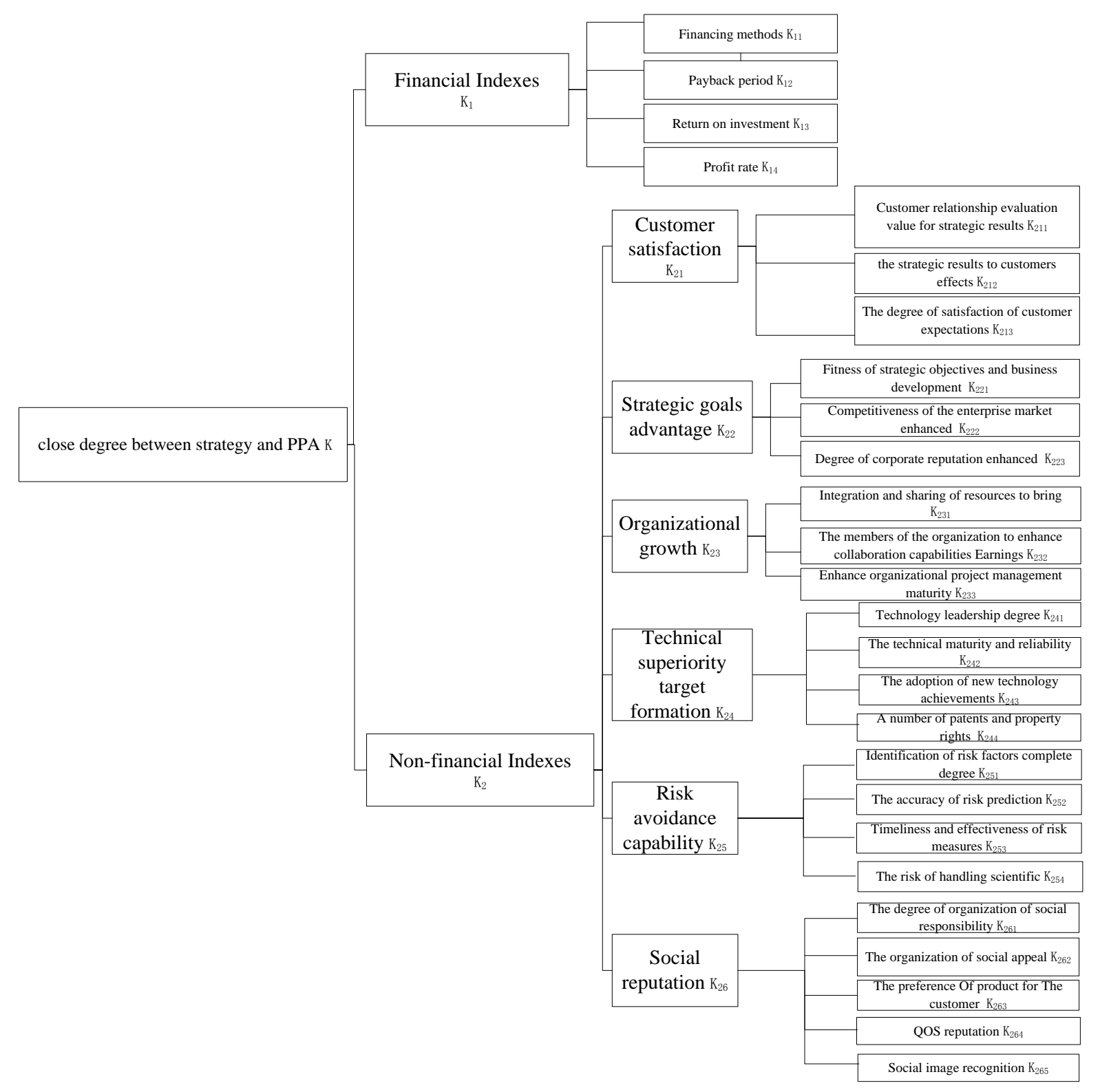

Figure 3. The system of evaluation indexes of the degree of closeness between strategy and PPA after optimization.

\section{Acknowledgements}

This study is sponsored by National Natural Science Foundation of China under Grant No.7117212 and Aviation Science Fund of China under Grant No. 2012ZG53083.

\section{References}

[1] Bertsimas, D., Gupta, S. and Lulli, G. (2014) Dynamic Resource Allocation: A Flexible and Tractable Modeling Framework. European Journal of Operational Research, 236, 14-26. http://dx.doi.org/10.1016/j.ejor.2013.10.063

[2] Fatemi Ghomi, S.M.T. and Ashjari, B. (2002) A Simulation Model for Multi-Project Resource Allocation. International Journal of Project Management, 20, 127-130. http://dx.doi.org/10.1016/S0263-7863(00)00038-7

[3] Otero, L.D., Centeno, G., Ruiz-Torres, A.J., et al. (2009) A Systematic Approach for Resource Allocation in Software Projects. Computers \& Industrial Engineering, 56, 1333-1339. http://dx.doi.org/10.1016/j.cie.2008.08.002

[4] Laslo, Z. and Goldberg, A.I. (2008) Resource Allocation under Uncertainty in a Multi-Project Matrix Environment: Is 
Organizational Conflict Inevitable? International Journal of Project Management, 26, 773-788. http://dx.doi.org/10.1016/j.ijproman.2007.10.003

[5] Gonçalves, J.F., Mendes, J.J.M. and Resende, M.G.C. (2008) A Genetic Algorithm for the Resource Constrained Multi-Project Scheduling Problem. European Journal of Operational Research, 189, 1171-1190. http://dx.doi.org/10.1016/j.ejor.2006.06.074

[6] Huang, W., Ding, L., Wen, B., et al. (2009) Project Scheduling Problem for Software Development with Random Fuzzy Activity Duration Times. Springer, Berlin, Heidelberg, 60-69.

[7] Ke, H. and Liu, B. (2010) Fuzzy Project Scheduling Problem and Its Hybrid Intelligent Algorithm. Applied Mathematical Modelling, 34, 301-308. http://dx.doi.org/10.1016/j.apm.2009.04.011

[8] Wang, W., Wang, X., Ge, X., et al. (2014) Multi-Objective Optimization Model for Multi-Project Scheduling on Critical Chain. Advances in Engineering Software, 68, 33-39. http://dx.doi.org/10.1016/j.advengsoft.2013.11.004

[9] Majazi Dalfard, V. and Ranjbar, V. (2012) Multi-Projects Scheduling with Resource Constraints \& Priority Rules by the Use of Simulated Annealing Algorithm. Tehnički Vjesnik, 19, 493-499.

[10] Zheng, Z., Shumin, L., Ze, G., et al. (2013) Resource-Constraint Multi-Project Scheduling with Priorities and Uncertain Activity Durations. International Journal of Computational Intelligence Systems, 6, 530-547. http://dx.doi.org/10.1080/18756891.2013.789152

[11] Singh, A. (2014) Resource Constrained Multi-project Scheduling with Priority Rules \& Analytic Hierarchy Process. Procedia Engineering, 69, 725-734. http://dx.doi.org/10.1016/j.proeng.2014.03.048

[12] Khoshjahan, Y., Najafi, A.A. and Afshar-Nadjafi, B. (2013) Resource Constrained Project Scheduling Problem with Discounted Earliness-Tardiness Penalties: Mathematical Modeling and Solving Procedure. Computers \& Industrial Engineering, 66, 293-300. http://dx.doi.org/10.1016/j.cie.2013.06.017

[13] Afshar-Nadjafi, B. and Majlesi, M. (2014) Resource Constrained Project Scheduling Problem with Setup Times after Preemptive Processes. Computers \& Chemical Engineering, 69, 16-25. http://dx.doi.org/10.1016/j.compchemeng.2014.06.012

[14] Jia, Q. and Seo, Y. (2013) Solving Resource-Constrained Project Scheduling Problems: Conceptual Validation of FLP Formulation and Efficient Permutation-Based ABC Computation. Computers \& Operations Research, 40, 2037-2050. http://dx.doi.org/10.1016/j.cor.2013.02.012

[15] Zhong, W.J. (2009) Theory and Methods for Enterprise Technology Innovation Management. Science Press, Beijing, 118-119.

[16] Du, X., Sun, S. and Ou, L. (2006) A Multi-Phase Framework of R\&D Project Balanced Portfolio Selection. Science of Science and Management of $S$ \& T, 11, 006.

[17] The Project Management Institute, Inc. (2004) A Guide to the Project Management Body of Knowledge. 3rd Edition, Vol. 11, Project Management Institute, Inc., Newtown Square, 245. 
Scientific Research Publishing (SCIRP) is one of the largest Open Access journal publishers. It is currently publishing more than 200 open access, online, peer-reviewed journals covering a wide range of academic disciplines. SCIRP serves the worldwide academic communities and contributes to the progress and application of science with its publication.

Other selected journals from SCIRP are listed as below. Submit your manuscript to us via either submit@scirp.org or Online Submission Portal.
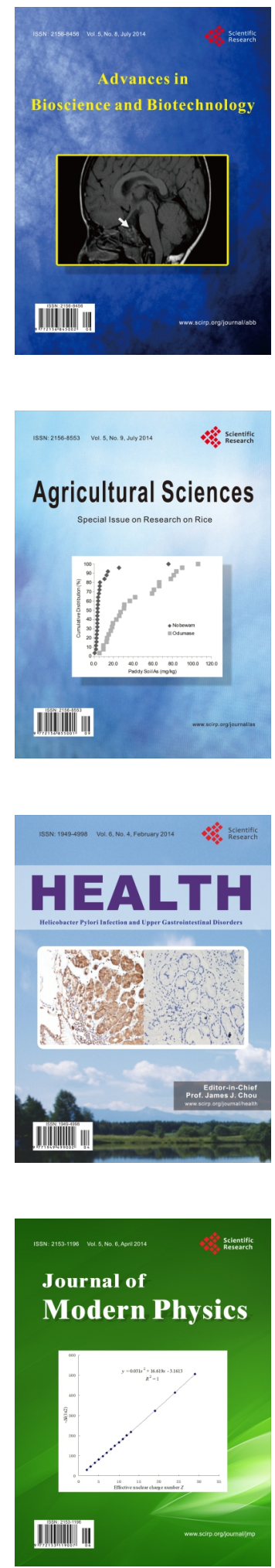
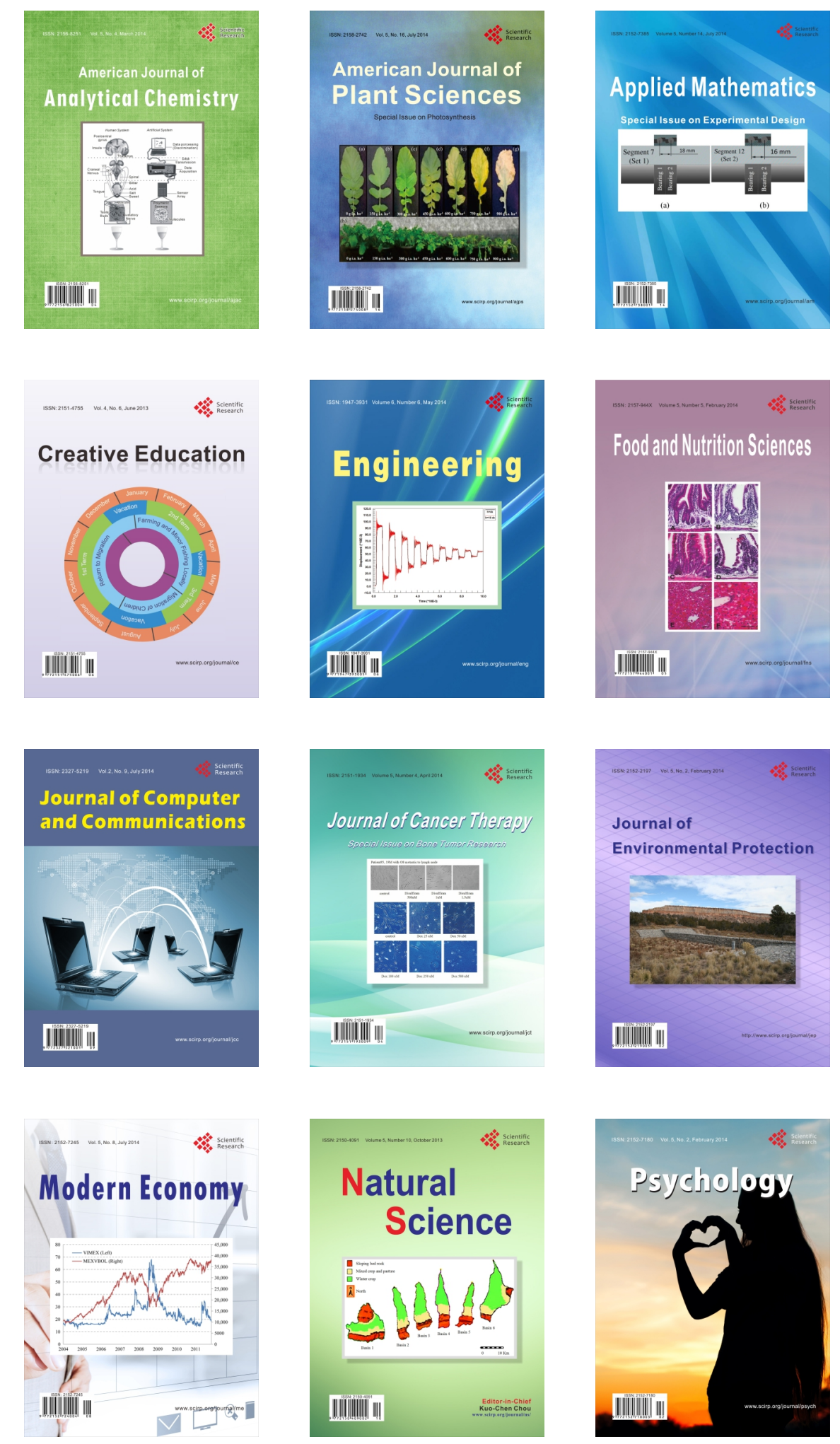